\title{
USING AFLP MARKERS FOR SPECIES DIFFERENTIATION AND ASSESSMENT OF GENETIC VARIABILITY OF IN VITRO-CULTURED PAPAVER BRACTEATUM (SECTION OXYTONA)
}

\author{
J. C. CAROLAN ${ }^{1}$, I. L. I. HOOK ${ }^{2}$, J. J. WALSH' ${ }^{2}$, AND T. R. HODKINSON ${ }^{1}$ \\ ${ }^{1}$ Department of Botany, University of Dublin, Trinity College, Dublin 2, Ireland \\ ${ }^{2}$ Department of Pharmacognosy, School of Pharmacy, University of Dublin, Trinity College, Dublin 2, Ireland
}

(Received 30 June 2001; accepted 29 November 2001; editor R.D. Shillito)

\begin{abstract}
Summary
Amplified fragment length polymorphism (AFLP) markers were employed to detect genetic variation among species of Papaver (section Oxytona) and assess genetic fidelity between in vitro cell lines of Papaver bracteatum and mature plants derived from the propagation of their callus cultures. Regenerated plants exhibited morphological and phytochemical characteristics dissimilar to those of their source material. Thebaine, the dominant alkaloid produced by Papaver bracteatum, was not detected in capsules from mature regenerated accessions, indicating that there may have been a loss of genetic uniformity. Instead, the dominant alkaloid produced by the regenerated plant was shown to be isothebaine (by TLC and GC/MS), a metabolic characteristic of $P$. pseudo-orientale. A Neighbor-Joining tree constructed from AFLP fingerprints distinctly separates the three species of Oxytona while firmly grouping the in vitro-cultured plants with $P$. pseudo-orientale. Additionally, phytochemical data and chromosome counts indicate that the seed used to initiate cultures was of hybrid origin and that the loss in genetic uniformity was not due to somaclonal variation occurring during the in vitro culture process. AFLP fingerprinting was therefore able to differentiate Oxytona species and investigate allopolyploidy in closely related Papaver species.
\end{abstract}

Key words: AFLP fingerprinting; isothebaine; Oxytona; regeneration; Papaver bracteatum; somaclonal variation; thebaine.

\section{INTRODUCTION}

The genus Papaver L. is of continuing commercial interest because of its medicinally important alkaloids. Papaver somniferum L. is grown for its morphine and codeine content, while Papaver bracteatum Lindl. can be used as a source of the morphinan alkaloid thebaine, which can be converted to a number of opiate analgesics, including codeine, oxymorphone, and oxycodone (McNicholas and Martin, 1984). During the 1970s, the United Nations called for extensive studies into the utilization of $P$. bracteatum as a source of thebaine and the possible replacement of $P$. somniferum as the major source of morphinan alkaloids (United Nations Report, 1976). However, the perennial nature of $P$. bracteatum renders it uneconomical as a replacement to the annual $P$. somniferum because it cannot be harvested until the second growing season (Ilahi and Ghauri, 1994). This has stimulated research into the potential of in vitro cell culture technologies for morphinane alkaloid production (Kamo and Mahlberg, 1988), which would obviate the need for field cultivation of poppies.

Papaver bracteatum is a member of the taxonomic section Oxytona which comprises a polyploid series including the diploid $P$. bracteatum $(2 n=14)$, the tetraploid $P$. orientale Fedde $(2 n=28)$, and the allohexaploid $P$. pseudo-orientale Fedde $(2 n=42)$. The three can be differentiated using morphological, cytological, and

\footnotetext{
*Author to whom correspondence should be addressed: Email carolaj@tcd.
}

phytochemical characters (Table 1) but the distinction is not always clear (Goldblatt, 1974; Nyman and Bruhn, 1979). Goldblatt (1974) reported that the morphological ranges of variation of $P$. bracteatum, $P$. orientale, and $P$. pseudo-orientale, when nearing their extremes, can often overlap, especially with $P$. orientale and $P$. pseudoorientale. Interspecific hybridization does occur (Goldblatt, 1974; Milo et al., 1986; Ojala et al., 1990; Levy and Milo, 1991) and due to phenotypic similarities, the misidentification of plant material used to initiate cell cultures is common. The identification of species within this section is therefore problematic and is exacerbated by the abundance of ornamental cultivars and garden varieties of 'oriental poppies' that have been developed.

Molecular techniques offer the potential to accurately differentiate species before initiating cultures and bypass the reliance on diagnostic morphological and phytochemical characters that take time to collect, since flowering and maturity do not occur until the second growing season for members of section Oxytona. Such techniques involve the generation of characteristic genetic fingerprints (or the detection of species-specific molecular markers), which are then used to differentiate between closely related species, varieties, and cultivars. Characteristic DNA fingerprints can be generated using amplified fragment length polymorphism (AFLP; Vos et al., 1995). AFLP fingerprinting is based on the selective amplification of restriction fragments from a digest of genomic DNA. The resulting complex fingerprints are reproducible and provide a wide number of informative markers derived from the many loci dispersed throughout the genome (Ridout and Donini, 1999; 
TABLE 1

DIAGNOSTIC MORPHOLOGICAL CHARACTERS USED TO DEFINE THE SPECIES OF PAPAVER SECTION OXYTONA (MANY OF THE CHARACTER STATES CAN OVERLAP AND CAUSE CONFUSION WHEN IDENTIFYING PLANTS TO THE LEVEL OF SPECIES)

\begin{tabular}{|c|c|c|c|}
\hline Character & Papaver bracteatum & Papaver orientale & Papaver pseudo-orientale \\
\hline Dominant alkaloid & Thebaine & Oripavine & Isothebaine \\
\hline Petal characteristics & Deep red, base black streak & Orange no markings & Orange/red black center \\
\hline Flowers & Bractate & Ebractate & Bractate/ebractate \\
\hline Petals & 6 rarely 4 & 4 rarely 6 & 4 or 6 \\
\hline Petal color & Dark red, dark markings running to base & Pale orange & Orange, black rectangular markings near base \\
\hline Leaves & Dentate-bidentate & Serrate & Deeply pinnatisect-subcompound \\
\hline Floral bracts & $3-8$ & Absent & $5-6$ \\
\hline Bud (during development) & Erect, oval, oblong before opening & Pendulous & Absent or present 1-4 Erect/oval \\
\hline Calyx & 3 -valved & 2 -valved & $2-3$-valved \\
\hline Bristles & Thick/adpressed & Slender/subpatent & Slender/subpatent \\
\hline Anthers & Linear/dark purple & Oblong/yellow or pale violet & Linear/pale violet \\
\hline Mean pollen diameter $(\mu \mathrm{m})$ & 25.5 & 27.4 & 28.8 \\
\hline Ovary & Ovoid & Ovoid & Ovoid \\
\hline Ovary disc & Flat/concave or conical & Slightly convex & Slightly convex \\
\hline Capsule & $\approx 3.0 \mathrm{~cm}$ wide & $\approx 2.0 \mathrm{~cm}$ wide & $\approx 2.5 \mathrm{~cm}$ wide \\
\hline
\end{tabular}

TABLE 2

PAPAVER MATERIAL USED IN STUDY

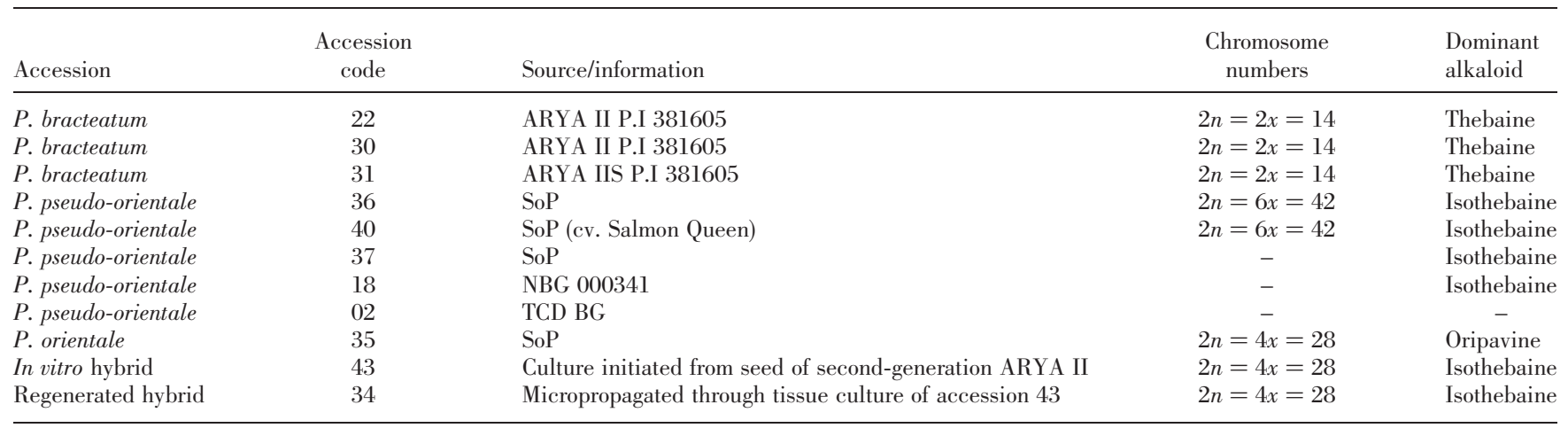

NBG: National Botanic Gardens, Glasnevin, Ireland; TCD BG: Trinity College Dublin, Botanic Gardens; SoP: School of Pharmacognosy, Department of Pharmacy, Trinity College Dublin.

Dominant alkaloids (identified by TLC and GC/MS) and chromosome numbers were counted for a selection of accessions.

Hodkinson et al., 2000). AFLP has been used to detect genetic variation in highly inbred lines of cereal crops and for the study of clonal variation in plants (Mackill et al., 1996; Paul et al., 1997; Waugh et al., 1997; Hodkinson et al., 2002). It has also been used for species differentiation in a range of higher plant species such as Phyllostachys (Hodkinson et al., 2000), but not in Papaver section Oxytona.

Several cell cultures were developed by Hook et al. (1988) from seeds of P. bracteatum originally supplied as ARYA II. Plants developed from these seeds exhibited morphological and phytochemical characteristics typical of $P$. bracteatum as described by Goldblatt (1974). On repeated subculture one cell line exhibited organogenesis, and subsequently differentiated into in vitro plantlets, some of which were grown on to maturity under garden conditions. The resulting plants did not resemble the parent, exhibiting morphological characters similar but not identical to those of $P$. pseudo-orientale. This therefore brought into question the identity of the original seed used to initiate the cultures or indicated that the cell culture process was not stable and had induced morphological change possibly via somaclonal variation.

The objectives of this work were to generate characteristic genomic fingerprints using AFLP, which could be used to differentiate between the three species of section Oxytona and detect their hybrids. We wished to develop a marker system capable of identifying the genetic constitution of in vitro-generated plants and assessing the stability and quality of repeatedly subcultured cell 


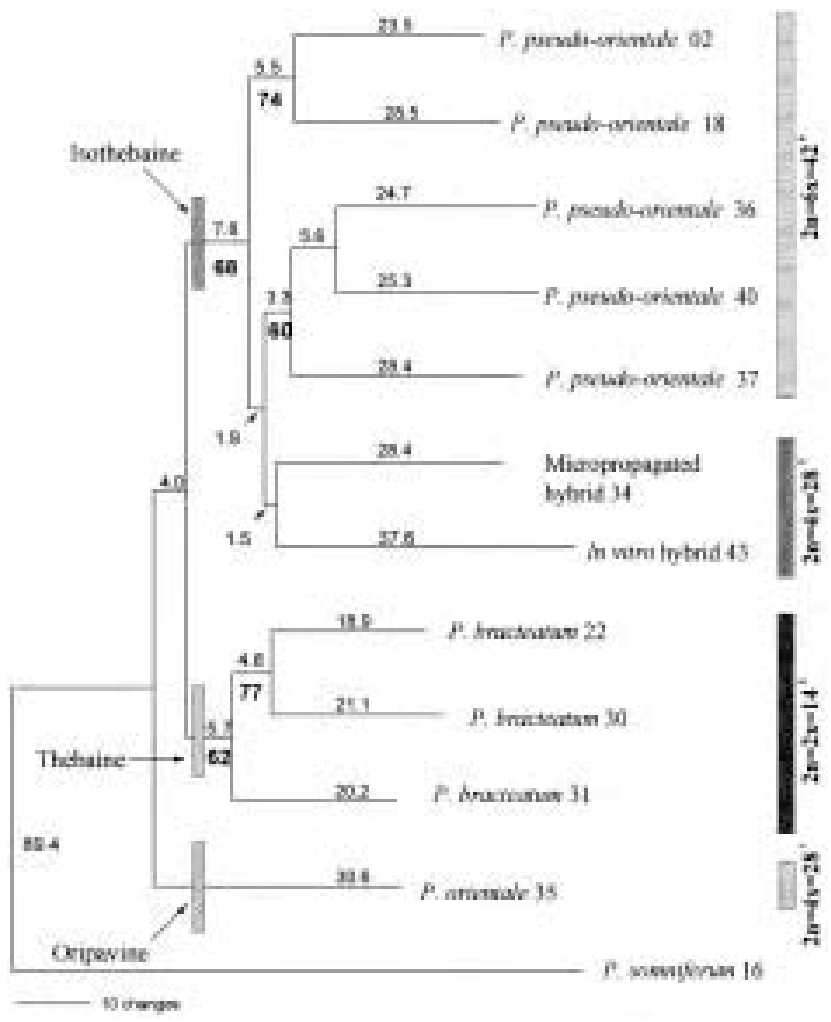

FIg. 1. Neighbor-Joining (NJ) tree based on AFLP data. The NJ tree has branches proportional to genetic distance (see scale bar). Three groups representing the three species of Oxytona are apparent. The in vitro plant and the regenerated plant resolve within the $P$. pseudo-orientale group. ${ }^{1}$ Based on chromosome count for accession 36. ${ }^{2}$ Based on chromosome count for accessions 34 and $43 .{ }^{3}$ Based on chromosome count for accessions 22 and 31 . ${ }^{4}$ Based on chromosome count for accession 35 .

lines. The collection of basic phytochemical (dominant alkaloid) and cytological data (chromosome counts) were to aid the interpretation of our results.

\section{Materials and Methods}

Plant material. Plant material was obtained from a number of sources listed in Table 2, and included four species: Papaver orientale, $P$. bracteatum, $P$. pseudo-orientale, and $P$. somniferum. Capsules were collected from mature plants from May to July 2000, 4 wk after flowering, and dried in a fan-assisted oven at $<35^{\circ} \mathrm{C}$. Not all accessions were available for alkaloid analysis and chromosome counts.

In vitro culture of Papaver bracteatum. Callus cultures were originally established in 1984 (Hook et al., 1988) from surface-sterilized seeds plated onto an agar-solidified (0.9\%) MS salt medium (Murashige and Skoog, 1962) containing 2,4-dichlorophenoxyacetic acid (2,4-D; $1 \mu M), \alpha$-naphthaleneacetic acid (NAA; $1 \mu M)$, glycine $(26.64 \mu M)$, nicotinic acid $(4.06 \mathrm{mM})$, pyridoxine $\mathrm{HCl}(2.43 \mu M)$, mesoinositol $(1.10 \mathrm{~m} M)$, thiamine $\mathrm{HCl}$ $(1.48 \mu M)$, and sucrose $(3 \%)$, using Technical Agar number 3 (Oxoid Ltd. UK). Cultures grew as beige-colored aggregates and were subcultured every 4-6 wk onto fresh medium. Subsequently, aggregates showing organogenesis were transferred to hormone-free MS agar where shoot and root regeneration occurred. Regenerated in vitro plantlets were also subcultured onto fresh medium every 4-6wk, and maintained to the present day. For alkaloid analysis, in vitro-grown plantlets were harvested after 6 wk growth and dried as above. Roots formed and these were used as the material for cytological analysis.
Cytological investigations. Seeds from identified accessions were germinated under constant light at $25^{\circ} \mathrm{C}$ on wet filter paper in plastic Petri dishes. Root tips were taken when growth reached $1.5 \mathrm{~cm}$. Chromosome counts were also made on young rapidly growing roots of in vitro-cultured plantlets. Root tips were pretreated in ice-cold water for $24 \mathrm{~h}$, fixed in $3: 1$ absolute ethanol:acetic acid and stored at $4{ }^{\circ} \mathrm{C}$ until use. Root tips were hydrolyzed in $1 \mathrm{~N} \mathrm{HCl}$ at $60^{\circ} \mathrm{C}$ for $8 \mathrm{~min}$, transferred into $5 \mathrm{ml}$ of Feulgen solution (Feulgen solution stains exposed aldehyde groups following hydrolysis), placed in the dark for $30 \mathrm{~min}$, and viewed with a light microscope at a magnification of $\times 1000$.

DNA extraction. DNA was extracted from $0.5 \mathrm{~g}$ of silica gel (Sigma) dried leaf material using a modification of the $2 \mathrm{XCTAB}$ procedure of Doyle and Doyle (1987) and precipitated using isopropanol for $24 \mathrm{~h}$ at $-20^{\circ} \mathrm{C}$. The DNA was then pelleted by centrifugation at $2000 \mathrm{rpm}$, washed with $70 \%$ ethanol, and stored in TE buffer $(10 \mathrm{~m} M$ Tris-HCl, $\mathrm{pH} 7.6$ and $1 \mathrm{~m} M$ EDTA) at $-80^{\circ} \mathrm{C}$. DNA was further purified using Concert PCR purification columns (Gibco BRL) and ranged in quantity from 70 to $250 \mathrm{ng} \mu \mathrm{l}^{-1}$, as estimated by fluorescence of ethidium bromide-stained DNA compared to known standards.

AFLP analysis. AFLP reactions used the AFLP Plant Mapping Kit of Applied Biosystems Inc. (ABI), following their standard protocols. Firstly, the restriction enzymes EcoRI and $M s e I$ were used to digest total genomic DNA. Oligonucleotide primers specific to these restriction sites were ligated to the fragments. Secondly, a preselective amplification was used according to the manufacturer's instructions. Thirdly, two primer combinations MseCTC/ EcoACG and MseCAG/EcoAGC were used for the selective PCR step (each including a fluorescently labeled primer), which amplified a subset of the fragments, created in the initial PCR. Finally, detection of DNA fragments was carried out on an ABI 377 Automated Sequencer with ABI Genescan 2.0.2.

Data analysis. AFLP profiles were scored using the Genotyper 1.1 software of ABI. DNA fragments ranging between 50 and 500 base pairs in size were scored as presence/absence characters and analyzed with Neighbor-Joining (NJ) using Nei and Li distances (Nei and Li, 1985) with the phylogenetic analysis program PAUP 4.0 (Swofford, 1998). Internal support for groupings was assessed using the bootstrap procedure with 1000 replicates (Felsenstein, 1985). Principal coordinates analysis (PCO) was performed with Le Progiciel R v4.0d (Casgrain, 1999) using Dice distances (Dice, 1945).

Alkaloid analysis. Mature, but unripe, poppy capsules were dried in a fan-assisted oven at $<35^{\circ} \mathrm{C}$. The stigmatic discs, seeds, and placentae were removed and samples were powdered, and $0.5 \mathrm{~g}$ of powdered capsule was extracted twice with $5 \%$ aqueous acetic acid $(50 \mathrm{ml})$ by shaking on an orbital shaker for $1 \mathrm{~h}$. The combined acid extracts were made alkaline to $\mathrm{pH} 9$ with $10 \%$ ammonium hydroxide and then extracted $(\times 3)$ with chloroform $(50 \mathrm{ml})$. The chloroform extracts were dried over anhydrous sodium sulfate, combined and evaporated in vacuo. The resultant residue was dissolved in $0.5 \mathrm{ml}$ methanol and examined by thin-layer chromatography (TLC) using silica gel plates (Silica gel $60 \mathrm{~F}_{254}$; Merck) developed in acetone:toluene:ethanol:conc. ammonia (40:40:12:2.5). Visualization of alkaloids was with UV light and Dragendorff's reagent. Reference compounds were thebaine $\left(2.0 \mathrm{mg} \mathrm{ml}^{-1}\right)$, isothebaine $\left(1.4 \mathrm{mg} \mathrm{ml}^{-1}\right)$, oripavine $\left(0.3 \mathrm{mg} \mathrm{ml}^{-1}\right)$, and salutaridine $\left(2.5 \mathrm{mg} \mathrm{ml}^{-1}\right)$.

For gas chromatographic mass spectrum (GC/MS) analysis, samples were injected in splitless mode onto a GC capillary column $(30 \mathrm{~m} \times 0.25 \mathrm{~mm}$ i.d., Va 35MS) coupled to a Saturn 2000 MSD (EI $70 \mathrm{eV}$ ). The injector temperature and the GC-MS transfer line was held at $260^{\circ} \mathrm{C}$ and the column programmed from $100^{\circ} \mathrm{C}$, held for $3 \mathrm{~min}$, rising to $300^{\circ} \mathrm{C}$ at $15^{\circ} \mathrm{C}$ per min. Helium was used as carrier gas at a flow rate of $1 \mathrm{ml} \mathrm{min}^{-1}$

\section{Results}

AFLP analysis. The two primer combinations from ALFP generated 254 polymorphic markers, of which 146 were shared between individuals. A NJ tree from the AFLP analysis, that groups accessions according to genetic similarity, is given in Fig. 1. There are three major divisions, representing the three species of section Oxytona, respectively ( $P$. orientale, $P$. bracteatum, and $P$. pseudoorientale). The in vitro-grown plant and the regenerated plant 


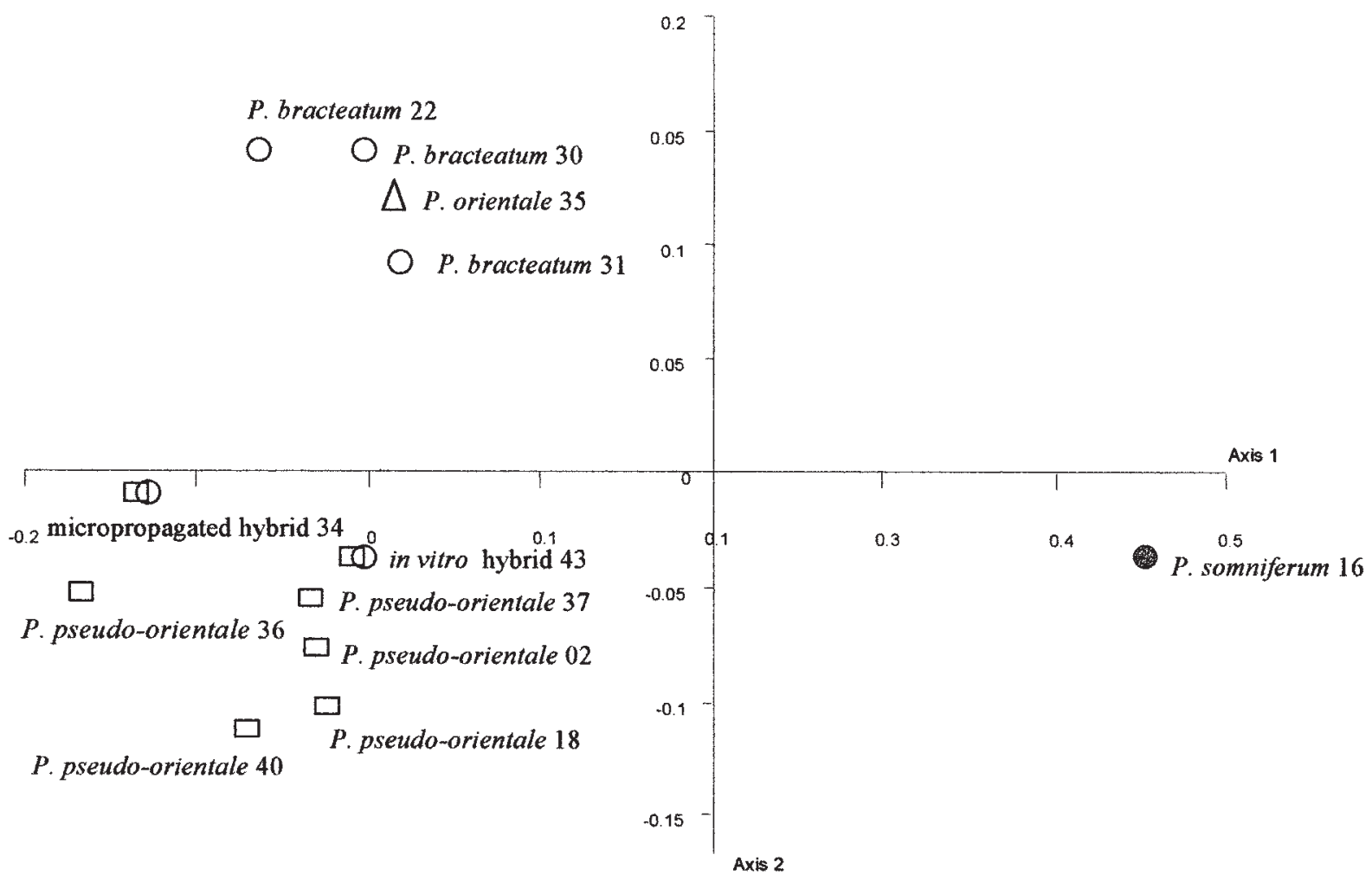

FIG. 2. Principal coordinates analysis (PCO) of AFLP data. The first two axes cumulatively accounted for $60.4 \%$ of the data variance (38.3 and 22.1, respectively). The in vitro plant and the regenerated plant group separately from the P. bracteatum accessions.

TABLE 3

SELECTED IONS, RETENTION TIMES, AND ION RATIOS OF PAPAVER ALKALOIDS: THEBAINE, ISOTHEBAINE, AND FOUR SELECTED ACCESSIONS

\begin{tabular}{lccc}
\hline Compound/accession & $\begin{array}{c}\text { Retention } \\
\text { time (min) }\end{array}$ & $\begin{array}{c}\text { Monitored } \\
\text { ions }\end{array}$ & $\begin{array}{c}\text { Ion ratio percentage } \\
\text { (abundance) }\end{array}$ \\
\hline Thebaine & 15.2 & 311,296 & 100,75 \\
Isothebaine & 16.0 & 311,294 & 100,50 \\
Accession 30 & 15.2 & 311,296 & 100,25 \\
Accession 31 & 15.2 & 311,296 & 100,25 \\
Accession 40 & 16.0 & 311,294 & 100,60 \\
Accession 43 & 16.0 & 311,294 & 100,60 \\
\hline
\end{tabular}

grouped with the $P$. pseudo-orientale accessions. Dendrograms produced for each set of primers separately were in congruence with the composite dendrogram for both primers.

The results of the PCO analysis are illustrated in Fig. 2. The first two axes cumulatively accounted for $60.4 \%$ of the data variance (representing 38.3 and 22.1, respectively). The PCO analysis is congruent with the $\mathrm{NJ}$ tree and shows that the in vitro-grown plant and the regenerated plant were distinct from Papaver bracteatum but shared the majority of markers with $P$. pseudo-orientale.

Alkaloid analysis. Alkaloid profiles for accessions where capsules were available are given in Table 2 . Reference standards of thebaine, isothebaine, oripavine, and salutaridine had $R_{f}$ values of $0.54,0.57,0.42$, and 0.46 , respectively. The in vitro-grown plant and the regenerated plant produced isothebaine $\left(R_{f}, 0.57\right)$ as the dominant alkaloid with several unidentified alkaloids present as minor constituents. For reference, capsules from $P$. bracteatum (accessions 22, 30, and 31 ) and $P$. pseudo-orientale (accessions 36 and 40$)$ produced thebaine $\left(R_{f}\right.$ value of 0.54$)$ and isothebaine $\left(R_{f}\right.$ value of 0.57 ) as dominant alkaloids, respectively, with $P$. orientale (accession 35$)$ producing oripavine $\left(R_{f}\right.$ value of 0.42$)$ as its dominant alkaloid.

To validate the TLC data, alkaloid extracts for selected accessions and standards were subjected to GC/MS. Their retention times and mass fragmentation spectra are given in Table 3. Papaver bracteatum (accessions 30 and 31) and P. pseudo-orientale (accession 40) produced thebaine (RT $15.2 \mathrm{~min}, \mathrm{~m} / \mathrm{z} 311$ ) and isothebaine (RT $16 \mathrm{~min}, \mathrm{~m} / \mathrm{z} 311$ ), respectively, as their dominant alkaloids. The extract from the $P$. bracteatum $\times P$. pseudo-orientale hybrid (accession 43) contained isothebaine (RT $16 \mathrm{~min}, \mathrm{~m} / \mathrm{z} 311$ ) as the dominant alkaloid (Table 3).

Cytological analysis. Cells from root tips of in vitro-cultured $P$. bracteatum contained 28 chromosomes as detected in metaphase of mitosis. Chromosome counts for available accessions are given in Table 2. Members of the $P$. bracteatum AFLP group were diploid with $2 n=14$, while members of the $P$. pseudo-orientale group were hexaploid with $2 n=42$ (excluding the hybrid). Papaver orientale had 28 chromosomes and is tetraploid $(2 n=28)$.

\section{Discussion}

Identification of a hybrid in vitro cell line using AFLP fingerprinting. The NJ tree generated from the AFLP markers 
showed three major groups, which correspond to the three species, P. bracteatum, P. orientale, and P. pseudo-orientale. Papaver bracteatum accessions resolved independently from a group which contains the P. pseudo-orientale accessions. Papaver orientale resolved as a sister group to the other two species but bootstrap support for this position is weak $(<50)$. The results of the PCO analysis are congruent with these conclusions. Accessions labeled as $P$. orientale shared morphological characters with $P$. pseudoorientale, having orange petals with large dark spots on each. These two accessions (02 and 18) grouped with other P. pseudo-orientale plants. AFLP-generated markers are therefore highly efficient when used in conjunction with morphological, phytochemical, and cytological characters to identify plant material.

Regenerated plantlets grown on from the $P$. bracteatum cultures should group with $P$. bracteatum if they have remained genetically stable before and during tissue culture. However, this in vitro-derived plantlet did not associate with $P$. bracteatum and instead grouped more closely with $P$. pseudo-orientale. These AFLP groupings show that genomic material from $P$. pseudo-orientale is present within the in vitro-grown plant and the micropropagated accession, indicating that a hybridization event may have occurred between $P$. pseudo-orientale and the maternal $P$. bracteatum, from which seed was obtained to initiate the in vitro plants. The in vitro plant and the regenerated accession group together but are not identical, which suggests that somaclonal variation may have occurred during their culture. AFLP-generated fingerprints would therefore have the potential to detect loss of genetic uniformity due to somaclonal variation in poppies. We are currently investigating them further in this regard.

The results from the alkaloid analysis (Tables 2 and 3) support the conclusion that the in vitro-grown plant is a hybrid. If the in vitro-grown plant bred true from $P$. bracteatum, thebaine would be the expected dominant alkaloid (Hook et al., 1988). Environmental influences and the genotype $\times$ environment interaction have considerable effects on the quantity of alkaloids produced by particular accessions (Bernath and Nemeth, 1998). However, for species of section Oxytona, phytochemical spectrum and to some extent alkaloid quantity are influenced primarily by parent genotype and ploidy (Milo et al., 1990; Levy and Milo, 1991). For example, hybrids between Oxytona species produce characteristic phytochemical spectra dependent on the inherited genetic information (Milo et al., 1990; Levy and Milo, 1991). The wide spectrum of alkaloids found in the differentiated in vitro plant (including isothebaine) demonstrates the presence of P. pseudo-orientale genomic material and its resulting biosynthetic pathways. Hybrids between $P$. bracteatum and P. pseudo-orientale have been reported to produce both isothebaine and thebaine, inherited from the two parental genotypes, respectively (Levy and Milo, 1991). Our results contrast with Levy and Milo (1991), as no traces of thebaine were recorded for the hybrid accession. The alkaloid spectrum found within each species is congruent with the groupings of the AFLP analysis with three groups all producing diagnostic dominant alkaloids.

To confirm that the material used to initiate the in vitro plant arose from hybrid seed, chromosomes were counted and compared to counts for other studied accessions. Papaver bracteatum, $P$. orientale, and P. pseudo-orientale had 14, 28, and 42 chromosomes, respectively. The in vitro plant had 28 chromosomes and is therefore a tetraploid. We have provided evidence to show that the cultured plant is likely to be an allopolyploid with genomes from both $P$. bracteatum and another species (probably $P$. pseudo-orientale). The hybrid clusters closer to $P$. pseudo-orientale than $P$. bracteatum (in both NJ and PCO analyses), which indicates that it might have inherited more chromosomes from $P$. pseudo-orientale than $P$. bracteatum. In this case, one explanation is that it inherited seven chromosomes from P. bracteatum and 21 from P. pseudo-orientale.

Goldblatt (1974) cites examples of Papaver (section Oxytona) hybrids with somewhat intermediate characteristics, and stresses that some of the diagnostic characters when used alone could lead to misidentifications. Hybrids are not always morphologically intermediate between their parents (Riesberg, 1995) and great care needs to be taken when evaluating their characters. They are often just as likely to exhibit the characteristics of one or other of the parental species. The regenerated plant resembled $P$. pseudo-orientale more closely in its gross morphology than $P$. bracteatum, having six orange petals with faded central purple spots. Single bracts were present but not found on all flowering stems. The two-valved calyx was borne on a pendulous flowering stem becoming erect when mature. Uncharacteristic fine setae were subpatent on the lower portion of the flowering stem, becoming adpressed further up. The capsule bore a concave stigmatic disc comprising 14 stigmatic rays. There was, therefore, little indication from morphological data that $P$. bracteatum was a parent to this particular accession. The original $P$. bracteatum plant had, in fact, been garden grown in the presence of $P$. pseudo-orientale and a hybridization event was possible. Molecular AFLP data in combination with chromosome counts confirm that such an event did occur. This is therefore an example of a situation where a hybrid is not morphologically intermediate between its parents as it inherited more characters from one of them.

In vitro technology and molecular markers. Genetic variation among micropropagated plants is well documented (Rani and Raini, 2000). Somaclonal variation, whether it is at the molecular, morphological, or the phytochemical level, must be detected and minimized if true-to-type plants are to be produced. The use of molecular techniques has allowed rapid detection of such variation and helped elucidate the mechanisms that cause the loss of genetic uniformity.

AFLP fingerprints are highly reproducible and generally produce a large number of polymorphic markers (Becker et al., 1995; Ridout and Donini, 1999; Hodkinson et al., 2000). We have demonstrated that they can be applied to the study of genetic variation in poppies. They have the potential to identify ambiguities between parent material and regenerated plantlets and to detect somaclonal variation in Papaver in vitro clones and propagated plants. In our research, the rapid identification of the hybrid cell line allowed us to review the various sources of plant material used to initiate callus and suspension cultures.

The mass propagation of high alkaloid-producing cell lines demonstrates one of the beneficial uses of in vitro technologies to the successful utilization of Papaver species. Papaver bracteatum plants are almost always self-incompatible, which makes the creation of phytochemically pure lines through selfing very difficult to achieve. Day et al. (1986) reported successful regeneration of micropropagated plants from embryogenic callus culture with little phytochemical variation occurring between micropropagated offspring and parent plant material. The effects of somaclonal variation, however, have the potential to diminish effectiveness of tissue culture as a means of producing significant quantities of genetically and 


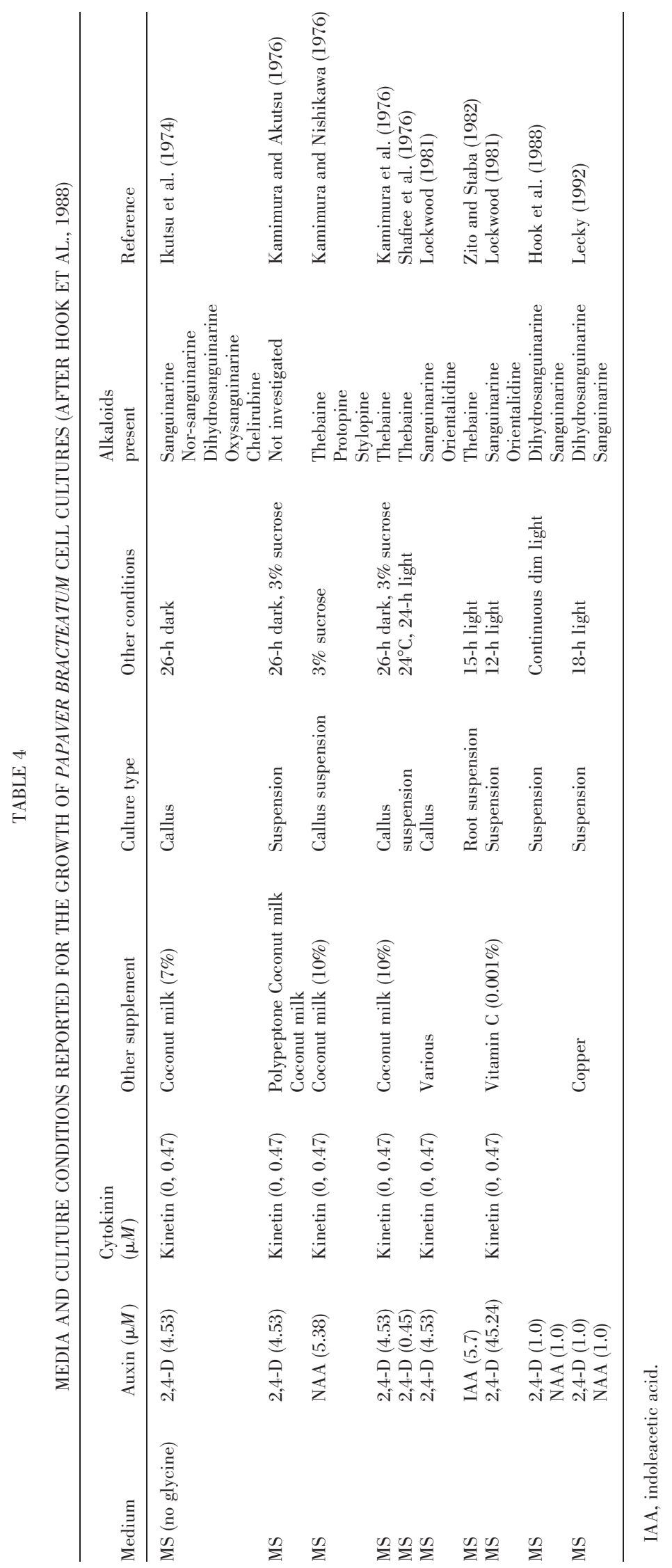


phytochemically uniform accessions. Additionally, seeds taken from mature plants grown under garden conditions have the potential of being of hybrid origin. If we had not established that the seeds used to initiate cultures were of hybrid origin and proceeded with our work on a larger scale, subculturing and mass propagation of this particular accession would have resulted in a crop of hybrids, none of which would have possessed thebaine, the desired phytochemical constituent.

In vitro production of alkaloids in Papaver bracteatum. There has been little substantial success in producing good yields of thebaine from callus or suspension cultures derived from poppy cells. The production of morphinan alkaloids is known to be associated with cell differentiation and morphogenetic processes (Constabel, 1985; Kutchan et al., 1985; Kamo and Mahlberg, 1988; Szoke, 1998). Morphinan alkaloid synthesis is dependent on the presence of specialized cells known as laticifers (Roberts et al., 1983; Kutchan et al., 1985; Rush et al., 1985), which are absent in undifferentiated poppy cultures. The detection of such alkaloids often coincides with the development of laticifers in differentiated plant material that develop in a similar way to young seedlings. The majority of reported alkaloids from callus and suspension Papaver bracteatum cultures are the benzophenanthridine type including sanguinarine, dihydrosanguinarine, and oxysanguinarine (Table 4), which are produced in minor quantities in intact plants of the genus Papaver but are found as the dominant constituents of undifferentiated callus and suspension cultures (Cline and Coscia, 1988). The biosynthesis of these alkaloids occurs at loci different to the laticifers associated with morphinan alkaloids (Kutchan et al., 1985). The characteristic phytochemical characters often used to aid species differentiation with species of section Oxytona are not produced by undifferentiated in vitro tissues. The use of genetic fingerprinting offers the potential to differentiate between closely related species, identify hybrid material, and assess the amount of genetic stability during the tissue culture processes.

The variability of alkaloids reportedly produced by the cell culture (Table 4) has often been explained by differences in growth conditions and by the degree of tissue differentiation. It is possible, however, that such variability could also be due to misidentification of the plant material used as the seed source (Phillipson et al., 1981). We witnessed a departure from the expected alkaloid profile of a $P$. bracteatum plant but were able to attribute this to misidentification. Unfortunately, other studies that report high variability in alkaloid profiles often fail to provide evidence for correct identification of their material.

\section{Conclusions}

The most fundamental requirement for the use of any plant species in the pharmaceutical industry is its correct identification. Poppy species belonging to section Oxytona are not sufficiently distinct to base identification solely on morphological characters. Regenerated Papaver plantlets from tissue culture could be grown on to maturity and identified using morphological characters and chromosome numbers but a growing period of $2 \mathrm{yr}$ is required to produce flowers. AFLPs combined with cytogenetic analysis offer a powerful way to rapidly differentiate species and identify potential hybrids. AFLP clearly has great potential as a way of monitoring the genetic stability of in vitro plants, particularly those that possess superior phytochemical traits and that are multiplied by tissue culture methods. We are also investigating the potential of flow cytometry (Rabinovitch, 1994; Wilkinson et al., 2000) for rapidly screening the ploidy level and genetic constitution of Papaver.

The DNA fingerprinting technique, AFLP, combined with standard cytogenetic techniques offers the possibility to improve the utilization of Papaver bracteatum as a pharmaceutical resource. The markers can be used for marker-aided selection and for the study of quantitative trait loci (Mackill et al., 1996; Paul et al., 1997; Waugh et al., 1997). We have also demonstrated that the markers have wider utility in the field of plant systematics for the study of hybridization and introgression in poppies.

\section{REFERENCEs}

Becker, J.; Vos, P.; Kuiper, M.; Salamini, F.; Heun, M. Combined mapping of AFLP and RFLP markers in barley. Mol. Gen. Genet. 249:65-73; 1995.

Bernath, J.; Nemeth, E. Physiological-ecological aspects. In: Bernath, J., ed. Poppy the genus Papaver. Medicinal and aromatic plants - industrial profiles, Chur, Switzerland: Hardwood Academic Publishers; 1998:65-91.

Casgrain, P. Le Progiciel Rv4.0dl. Development release; 1999.

Cline, S. D.; Coscia, C. J. Stimulation of sanguinarine production by combined fungal elicitation and hormonal deprivation in cell suspension culture of Papaver bracteatum. Plant Physiol. 86:161-165; 1988.

Constabel, F. Morphinan alkaloids from plant cell cultures. In: Phillipson, J. D.; Roberts, M. F.; Zenk, M. H., eds. The chemistry and biology of isoquinoline alkaloids. Berlin: Springer; 1985:257-264.

Day, K. B.; Draper, J.; Smith, H. Plant regeneration and thebaine content of plants derived from callus culture of Papaver bracteatum. Plant Cell Rep. 5:471-474; 1986.

Dice, L. R. Measures of the amount of ecological association between species. Ecology 76:295-302; 1945.

Doyle, J. J.; Doyle, J. L. A rapid DNA isolation procedure for small quantities of fresh leaf tissue. Phytochem. Bull. Bot. Soc. Am. 19:11-15; 1987.

Felsenstein, J. Confidence limits on phylogenies: an approach using the bootstrap. Evolution 39:783-791; 1985.

Goldblatt, P. Biosystematic studies in Papaver section Oxytona. Ann. Mo. Bot. Gard. 61(2):264-296; 1974.

Hodkinson, T. R.; Chase, M. W.; Renvoize, S. A. Characterisation of a genetic resource collection of Miscanthus using AFLP and ISSR PCR. Ann. Bot. (in press); 2002.

Hodkinson, T. R.; Renvoize, S. A.; Ni Chonghaile, G.; Stapleton, M. A. Chase, M. W. A comparison of ITS nuclear rDNA sequence data and AFLP markers for phylogenetic studies in Phyllostachys (Bambusoideae, Poaceae). J. Plant Res. 113:259-269; 2000.

Hook, I.; Sheridan, H.; Wilson, G. Alkaloids of the cell cultures derived from strains of Papaver bracteatum. Phytochemistry 27:2137-2141; 1988.

Ikutsu, A.; Syono, K.; Furuya, T. Alkaloids of callus tissues and redifferentiated plantlets in the Papaveraceae. Phytochemistry 27:2175-2179; 1974

Ilahi, I.; Ghauri, E. G. Regeneration in cultures of Papaver bracteatum as influenced by growth hormones and temperature. Plant Cell Tiss. Organ Cult. 38:81-83; 1994.

Kamimura, S.; Akutsu, M. Cultural conditions on growth of the cell culture of Papaver bracteatum. Agric. Biol. Chem. 40(5):899-906; 1976.

Kamimura, S.; Akutsu, M.; Nishikawa, M. Formation of thebaine in the suspension culture of Papaver bracteatum. Agric. Biol. Chem. 40(5):913-919; 1976.

Kamimura, S.; Nishikawa, M. Growth and alkaloid production in the cultured cells of Papaver bracteatum. Agric. Biol. Chem. 40(5):907-911; 1976.

Kamo, K. K.; Mahlberg, P. G. Morphinan alkaloids: biosynthesis in plant (Papaver spp.) tissue culture. In: Bajaj, Y. P. S., ed. Biotechnology in agriculture and forestry 4 . Medicinal and aromatic plants I. Berlin: Springer-Verlag; 1988:251-263.

Kutchan, T. M.; Ayabe, S.; Coscia, C. J. Cytodifferentiatiation and Papaver 
alkaloid accumulation. In: Phillipson, J. D.; Roberts, M. F.; Zenk, M. H., eds. The chemistry and biology of isoquinoline alkaloids. Berlin: Springer; 1985:281-294.

Lecky, R. Biotechnological evaluation of Papaver bracteatum cell cultures. PhD thesis, Trinity College Dublin; 1992.

Levy, A.; Milo, J. Inheritance of morphological and chemical characters in interspecific hybrids between Papaver bracteatum and Papaver pseudo-orientale. Theor. Appl. Genet. 81:537-540; 1991.

Lockwood, B. Orientalidine and isothebaine from cell cultures of Papaver bracteatum. Phytochemistry 20:1463-1464; 1981.

Mackill, D. J.; Zhang, Z.; Redona, E. D.; Colowit, P. M. Level of polymorphism and genetic mapping of AFLP markers in rice. Genome 39:969-977; 1996

McNicholas, L. F.; Martin, R. New and experimental therapeutic role for naloxone and related opiate antagonists. Drugs 27:81-93; 1984.

Milo, J.; Levy, A.; Ladizinsky, G.; Palevitch, D. Phylogenetic studies in Papaver section Oxytona: cytogenetics of the species and interspecific hybrids. Theor. Appl. Genet. 75:795-802; 1986.

Milo, J.; Levy, A.; Palevitch, D.; Ladizinsky, G. Genetic evidence for the conversion of the morphinan alkaloid thebaine to oripavine in interspecific hybrids between Papaver bracteatum and Papaver orientale. Heredity $64: 367-370 ; 1990$.

Murashige, T.; Skoog, F. A revised medium for rapid growth and bioassays with tobacco tissue cultures. Physiol. Plant. 15:473-497; 1962.

Nei, M.; Li, W. H. Mathematical model for studying genetic variation in terms of restriction nucleases. Proc. Natl Acad. Sci. USA 76:5269-5273; 1985.

Nyman, U.; Bruhn, J. G. Papaver bracteatum - a summary of current knowledge. Planta Med. 35:97-117; 1979.

Ojala, A.; Rousi, A.; Lewing, E.; Pyysalo, H.; Widen, C. J. Interspecific hybridization in Papaver III. F1 hybrids between species of section Oxytona. Hereditas 112:221-230; 1990.

Paul, S.; Wachira, F. N.; Powell, W.; Waugh, R. Diversity and genetic differentiation among populations of Indian and Kenyan tea (Camellia sinensis (L.) O. Kuntze) revealed by AFLP markers. Theor. Appl. Genet. 94:255-263; 1997.

Phillipson, J. D.; Scutt, A.; Baytop, A.; Ozhatay, N.; Shariyar, G. Alkaloids from Turkish samples of Papaver orientale and P. pseudo-orientale. Planta Med. 43:261-271; 1981.
Rabinovitch, P. S. Flow cytometry. Methods Cell Biol. 41:264-496; 1994.

Rani, V.; Raini, S. N. Genetic fidelity of organized meristem-derived micropropagated plants: a critical reappraisal. In Vitro Cell. Dev. Biol. Plant 36:319-330; 2000.

Ridout, C. J.; Donini, P. Use of AFLP in cereals research. Trends Plant Sci. 4(2):76-79; 1999.

Riesberg, L. H. The role of hybridization in evolution: old wine in new skins. Am. J. Bot. 82:944-953; 1995.

Roberts, M. F.; McCarthy, D.; Kutchan, T. M.; Coscia, C. J. Localisation of enzymes and alkaloid metabolites in Papaver latex. Arch. Biochem. Biophys. 222:599-609; 1983.

Rush, M. D.; Kutchan, T. M.; Coscia, C. J. Correlation of appearance of morphinan alkaloids and laticifer cells in germinating Papaver bracteatum seedlings. Plant Cell Rep. 4:237-240; 1985.

Shafiee, A.; Lalezari, I.; Yassa, N. Thebaine in tissue culture of Papaver bracteatum Lindl. Population Arya II. Lloydia 39:380-381; 1976.

Swofford, D. L. Phylogenetic analysis using parsimony and other methods (PAUP), version 4.0. Sunderland, MA: Sinauer Associates; 1998.

Szoke, E. In vitro Biosynthesis of poppy alkaloids. In: Bernath, J., ed. Poppy the genus Papaver. Medicinal and aromatic plants - industrial profiles. Chur, Switzerland: Hardwood Academic Publishers; 1998:189-207.

United Nations Document. Scientific Research on Papaver bracteatum. Report of the Fourth Working Group. ST/SOA/SER.J/23; 1976:6.

Vos, P. R.; Hodges, R.; Bleeker, M.; Reijans, M.; van de Lee, T.; Hornes, M.; Frijters, A.; Pot, J.; Kuiper, M.; Zabeau, M. AFLP: a new technique for DNA fingerprinting. Nucleic Acids Res. 23:4407-4410; 1995.

Waugh, R.; Bonar, N.; Baird, E.; Thomas, B.; Graner, A.; Hayes, P.; Powell, W. Homology of AFLP products in three mapping populations of barley. Mol. Gen. Genet. 255:311-321; 1997.

Wilkinson, M. J.; Davenport, I. J.; Charters, Y. M.; Jones, A. E.; Allainguillaume, J.; Butler, H. T.; Mason, D. C.; Raybould, A. F. A direct regional scale estimation of transgene movement from genetically modified oilseed rape to its wild progenitors. Mol. Ecol. 9:983-991; 2000.

Zito, S. W.; Staba, E. J. Thebaine from root cultures of Papaver bracteatum. Planta Med. 45:53-54; 1982. 